\title{
Circuit Modeling and Analysis of Wearable Antennas on the Effect of Bending for Various Feeds
}

\author{
Sandhya Mallavarapu \\ Department of Electronics \& Communication Engineering \\ National Institute of Technology Warangal \\ Warangal, Telangana, India \\ sandhyamallavarapu@student.nitw.ac.in
}

\author{
Anjaneyulu Lokam \\ Department of Electronics \& Communication Engineering \\ National Institute of Technology Warangal \\ Warangal, Telangana, India \\ anjan@nitw.ac.in
}

\begin{abstract}
The promising utilization of wearable antennas has experienced gigantic growth during the last decade. An antenna is one of the most significant and crucial components of wireless wearable devices. They need to be particularly designed to work while worn on and off the body. The wearable antenna embedded into clothing finds its use in wireless communications including tracking and navigation, mobile and wearable computing, and public safety and security. For user accessibility, there is a growing requirement for incorporating antennas on or in clothing. Determining the dielectric characteristics of the flexible substrates utilized in the design of the wearable antenna is also essential. In this paper, a Microstrip Ring Resonator (MRR) is employed to determine the dielectric properties of fabric substrates followed by state-of-the-art designs of wearable antennas and their bending effects at ISM band frequencies. An electrical equivalent model is designed to realize the potentials inside the geometry of an antenna under bending environment. This is followed by observing the effect of bending for different feeding methods on the wearable antenna's parameters when bending on a certain radius. The robustness of the proposed wearable antenna is examined by measuring the antenna under various bending curvatures for return loss, gain, and efficiencies. This will disclose the various contemplations for designing a wearable antenna from different feeding mechanisms with different materials and exemplifying the antenna's outcomes to dynamic moments of the human body. The performance of the proposed wearable antenna is acceptable even in a deformation environment, and there is a good agreement between the measured and the simulation results.
\end{abstract}

Keywords-wearable antenna; Wireless Body Area Networks (WBAN); Microstrip Ring Resonator (MRR); industrial; Scientific and Medical (ISM) band; Aperture Coupled Wearable Antenna (ACWA)

\section{INTRODUCTION}

The evolution of wearable antennas originates from the concept of wearable computing systems as a part of clothing that enables the wearer continuous hassle-free data transfer. In recent times, a wearable antenna receives a noteworthy development in technologies such as Wi-Fi, Bluetooth, Wireless Local Area Networks (WLANs), and Wireless Body Area Networks (WBANs). In general, a wearable antenna is stated to have high flexibility and competence in a system connected with the human body. Well-being, health, and lifestyle are the primary interests while implementing these systems [1-5]. Usually, wearable antenna desires for all modern applications must be lightweight, economical, almost maintenance-free, and do not require installation. Several specialized activity segments apply body area communication network systems, for instance, paramedics [6], firefighters [7], astronautics [8], military [9], and public safety. In addition, wearable antennas can also be applicable for teenagers, the elderly, and sportspersons to monitor vital signs such as temperature, heart rate, etc.

When worn on the body, wearable antennas can establish a wireless link between the body and the external world. The most appropriate topology for wearable antennas, ensuring the most favorable integration into clothing and wearer's ease, is the planar patch antenna $[8,9]$. On-body antennas are preferably made of flexible textiles and wearable materials [12], which can naturally conform to the surface of the body. This involves information related to the dielectric characteristics, namely permittivity and loss tangent of the fabric. The measurement of the dielectric properties of flexible materials characterized by their complex values is a challenging task and special measuring instruments are required [13]. A simple but effective technique is considered to characterize the flexible substrates and electromagnetic properties of some fabrics $[14,15]$. Wearable antennas are usually designed in the ideal flat state. Still, when integrated into clothing and worn they are likely to be subjected to deformations such as bending and stretching, which cause variations in the performance of the antenna, leading to potential performance degradation related to the resonant frequency, impedance bandwidth, and efficiency [16, 17]. Though the antenna is designed for a certain curvature, the variation of the radius of the curvature can influence the antenna's performance. Therefore there is a need to explore the influence of bending on various factors starting from scratch. The effect of bending on the antenna performance is sensitive to the different dielectric value of substrates [18], in which the dielectric constant near the air shows stable performance under bending. The impact of different thicknesses is explored in [19], and the influence of different radiator shapes is explored in [20]. Further, the wearable antenna undergoes the effect of being near to the body as the relative permittivity of the body changes [21]. To mitigate the human body coupling, 
Electromagnetic Bandgap (EBG) structures / AMC structures are placed on the backside of the wearable antenna, which can improve its FBR [22].

Therefore, the fundamental step in ensuring that the antenna can perform well is to ascertain the most suitable feeding method [23]. Mostly, any efficient antenna design involves a maximum power transfer between the end terminals, i.e. from the source to the antenna, where the antenna is fed at a point where the antenna impedance is $50 \Omega$. By considering these conditions, the wearable antenna should be designed carefully in every aspect, including the feeding mechanism. However, the approach of estimating the antenna behavior using electromagnetic simulators has relatively high computational costs depending on the complexity of the radiating structure. Thus, an electrical equivalent circuit model is useful while characterizing such complex structures. In addition, the matching potentials of the antenna are estimated with the knowledge of equivalent circuit models. In this paper, the Advanced Design System (ADS) software is utilized to develop the equivalent circuit and predict the return loss, while the antenna is simulated in CST MW software before fabrication.

\section{DIELECTRIC PROPERTIES OF FABRICS}

Several techniques are available in the literature to identify the dielectric properties of fabrics. One simple technique adopted here is the Microstrip Ring Resonator (MRR), which is useful for analyzing the electromagnetic properties of the materials due to its feasible geometry, ease in prototyping, low price, small volume, and adaptability [24, 25]. The proper usage of the fabric material as substrate while designing wearable low-profile antennas makes them efficient. The MRR method uses the resonant frequency and the quality factor to calculate the permittivity and loss tangent of the substrate, which gives accurate results due to the absence of end effects and the high $\mathrm{Q}$ factor. This makes the proposed method advantageous compared to previously published [26, 27] methods. A straightforward resonant technique to characterize sample fabric's electromagnetic properties is based on the MRR and another method is based on the patch radiator, which is used to validate the results of the first. The geometry of the MRR involves the ring and two feed lines separated by a gap $(\Delta)$, which are placed on top of the substrate of size $50 \times 50 \mathrm{~mm}^{2}$. On the back of the substrate, ground plane is placed. Adhesive copper foil is utilized for the metal parts such as the ring and the two feed lines, whereas flexible jeans is the substrate as shown in Figure 1. The optimized dimensions are obtained with the help of traditional equations (Table I).

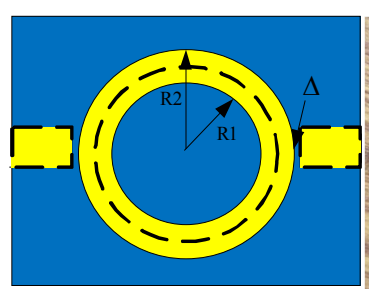

(a)

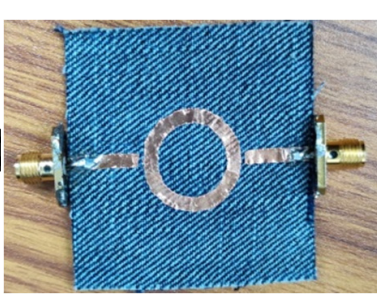

(b)
Fig. 1. (a) Schematic of the MRR, (b) prototype.
TABLE I. OPTIMIZED DIMENSIONS OF THE MRR MODEL

\begin{tabular}{|c|c|c|c|c|}
\hline Ring dimensions & $\begin{array}{c}\text { Mean } \\
\text { radius }(r)\end{array}$ & $\begin{array}{c}\text { Feed line } \\
\text { width }\left(W_{f}\right)\end{array}$ & $\begin{array}{c}\text { Feed line } \\
\text { length }\left(L_{f}\right)\end{array}$ & Gap $(\Delta)$ \\
\hline Value (mm) & 8.5 & 3 & 14 & 1 \\
\hline
\end{tabular}

Theoretically, the $n^{\text {th }}$ resonance peak takes place at [28]:

$$
F_{n}=\frac{n c}{2 \pi R \sqrt{\varepsilon_{r}}}
$$

where $R$ is the average radius, $c$ is the speed of light in the vacuum, and $\varepsilon_{r}$ is the required dielectric constant.

Also, the Insertion Loss (IL) $\mathrm{S}_{21}(\mathrm{~dB})$ is given by:

$$
\mathrm{IL}=20 \log \left[1-\frac{Q_{l}}{Q_{u}}\right]
$$

where $Q_{l}, Q_{u}$ represent the loaded and unloaded quality factors respectively.

From the $\mathrm{S}_{21}$ curve, the loaded quality factor given by:

$$
Q_{l}=\frac{f_{0}}{\Delta f}
$$

where $f_{0}$ is the resonance frequency, $\Delta f$ is the difference between the upper and lower of the $\mathrm{S}_{21}(\mathrm{~dB})$ curve.

The loss tangent can be calculated by determining the unloaded quality factor $Q_{u}$ from (2) and substitute in (4):

$$
\begin{gathered}
\frac{1}{Q_{u}}=\frac{1}{Q_{c}}+\frac{1}{Q_{d}} \\
Q_{c}=h \sqrt{f_{0} \mu_{0} \pi \sigma_{c}}
\end{gathered}
$$

where $Q_{d}$ and $Q_{c}$ are the quality factors of the dielectric and the conductor respectively.

Then, the loss tangent is calculated from:

$$
\tan \delta=\frac{1}{Q_{d}}
$$

Figure 2 shows the measurement setup on the network analyzer and the transmission coefficient of the proposed method. It is observed that there are two resonance peaks obtained at $4.27 \mathrm{GHz}$ and $8.9 \mathrm{GHz}$, with a corresponding return loss of -35.94 and $-22.48 \mathrm{~dB}$ for the jeans textile. Based on the resonant peaks that appeared in $\mathrm{S}_{21}$, the dielectric properties are calculated by substituting in (1)-(6) (Table II). The simulated and measured values are in good agreement. This result is also verified by the second method, which is focused on designing the patch antenna on the desired substrate [14].

In general, the fabric material is said to be lossless when the loss tangent is significantly small. According to the obtained results, the dielectric constant and loss tangent are 1.729 and 0.025 respectively [29-30]. Usually, the substrate's relative permittivity plays a substantial part in the design of the antenna, and variations in its value tend to change the operating 
frequency of the antenna to more or less of the desired center frequency. However, the variation in loss tangent has a negligible effect on the antenna resonant frequency, affecting mostly the magnitude of return loss.

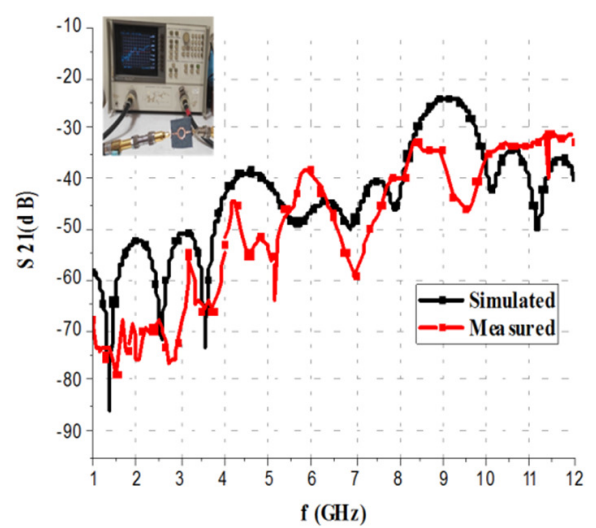

Fig. 2. S21 (dB) Vs. frequency of the MRR mode.

TABLE II. RESULTANT DIELECTRIC PROPERTIES OF JEANS SUBSTRATE USING THE MRR METHOD

\begin{tabular}{|c|c|c|c|c|}
\hline Mode & $\begin{array}{c}\text { Resonant } \\
\text { frequency (GHz) }\end{array}$ & IL S21 (dB) & $\begin{array}{c}\text { Dielectric } \\
\text { constant }\left(\boldsymbol{\varepsilon}_{\boldsymbol{r}}\right)\end{array}$ & $\tan \boldsymbol{\delta}$ \\
\hline$n=1$ & 4.2716 & -35.94322 & 1.729 & 0.078 \\
\hline$n=2$ & 8.916 & -24.9838 & 1.687 & 0.025 \\
\hline
\end{tabular}

\section{DESIGN AND ELECTRICAL EQUIVALENTS OF THE WEARABLE ANTENNA}

Ideally, a wearable antenna should be highly flexible, lightweight, and small in volume. It should have no installation requirements, high durability, and support bending and stretching at certain strain levels, but simultaneously it must be able to still function efficiently without compromising its RF characteristics. Two wearable antennas were designed with different feeding mechanisms and their equivalent circuits were obtained.

\section{A. Inset Fed Wearable Antenna}

For the implementation of a textile antenna, a planar patch antenna of a rectangular shape is chosen because of its planar structure and compactness [31]. Substrate selection is the key parameter while designing a microstrip antenna. By proper selection of the substrate dielectric properties and dimensions, a good antenna design is possible. The elementary form of the microstrip patch antenna consists of two metallic layers and a dielectric layer sandwiched between them as shown in Figure 3. The full ground plane attached to the back of the substrate shields the user from unwanted radiation. The radiating patch and the feed line are attached to the top of the substrate. The patch antenna with the inset feed is designed with flexible jeans as substrate and adhesive copper foil as the radiating patch. The proposed wearable patch antenna is designed to resonate at $2.5 \mathrm{GHz}$, which is suitable for Wi-Max applications. The transmission line model is used to find the input impedance of the inset-fed microstrip patch antenna. The microstrip patch antenna operates on the same principle, where the length of the patch has a greater influence in deciding the resonant frequency. The fringing fields' forms at both the ends along the length of the patch tend to increase the effective length of the patch. Therefore, the impedance at the edges is very high and decreases as the inset distance moves towards the center of the patch. By adjusting the inset distance, proper impedance matching is achieved. The optimized dimensions are obtained from the standard equations [32] as shown in Table III. To get more insight, the textile antenna can be described in its electrical equivalent. Using the transmission line model in [32], the equivalent circuit of the inset-fed patch element is modeled as a parallel RLC resonant network with a series inductance representing the near field effect of the microstrip feed line. The electromagnetic fields' parameters $L$ and $C$ can be determined in the antenna's near field, where they can represent the ability to deposit magnetic and electric energy in the circuit throughout resonance. The circuit simulations were carried out in ADS software. The optimized parameter values are directly shown with the elements in the circuit in Figure 4.

TABLE III. DIMENSIONS OF THE INSET FED WEARABLE PATCH ANTENNA

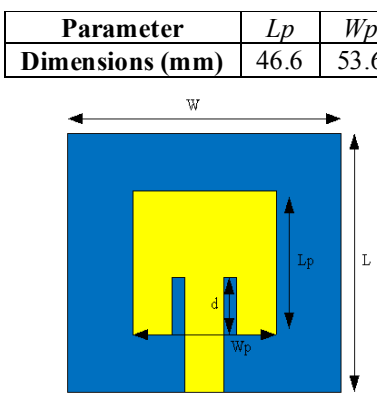

(a)

\begin{tabular}{|c|c|c|c|}
\hline$W$ & $L$ & Feed width & Thickness \\
\hline 100 & 100 & 13 & 3.5 \\
\hline
\end{tabular}

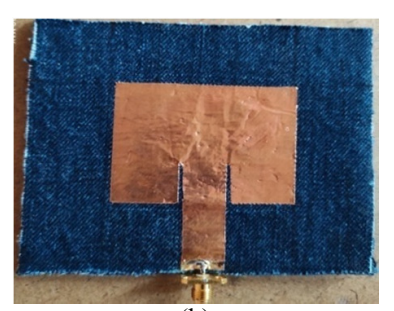

(b)
Fig. 3. (a) Schematic view, (b) fabricated prototype of the inset fed wearable patch antenna.

(a)

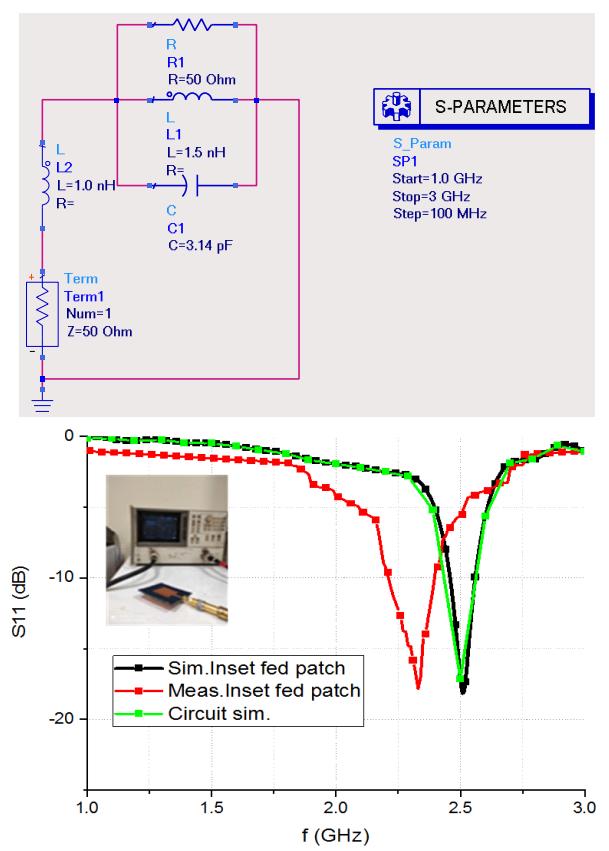

Fig. 4. (a) Simulated equivalent circuit in ADS, (b) S11 plot of the inset fed microstrip patch antenna. 
From the circuit, the feed point impedance at the specific frequency band can be modeled as an inductance $(L)$ at highfrequency and a capacitor at low-frequency (which is neglected and not shown in the circuit) in series. The circuit parameters $R_{a}, L_{a}$, and $C_{a}$ are the equivalent resistance, inductance, and capacitance and are given by the standard relations given below [33]:

$$
\begin{gathered}
C_{a}=\frac{\varepsilon_{e} \varepsilon_{0} L_{p} W_{p}}{2 h} \cdot \frac{1}{\cos ^{2}(\beta)}, \beta=\frac{\pi Z o}{L_{p}} \\
L a=\frac{1}{2 \pi f_{r} C_{a}} \\
R a=\frac{Q}{2 \pi f_{r} C_{a}}
\end{gathered}
$$

The input impedance at the feed location from the circuit is noted as:

$$
Z_{i n}(f)=\frac{1}{\frac{1}{R_{a}}+\frac{1}{j w L_{a}}+j w C_{a}}+X_{f}
$$

where $L_{p}$ is the length of the patch, $W_{p}$ the width of the patch, $h$ the substrate thickness and $\mathrm{Z}_{0}$ the feed location impedance.

From Figure 4(b), it is observed that there is a good agreement between the simulated and the measured values. However, a small discrepancy is accountable for fabrication errors. With a flexible substrate, it is always a challenging task to shape the material in the required dimensions with the help of scalpel/cutting tools. While cutting the edges of the substrate, due to parallax error, the slides and edges may not be straightly cut or some threads may come out. All these complications may affect the antenna matching and performance. Therefore the wearable antenna is fabricated with the right tools and with utmost care.

\section{B. Aperture Coupled Wearable Patch Antenna}

The present generation clothing can monitor the bio signals of the wearer and enables continuous communication between the attached antenna and the outer world regarding the person's state of health. Many of the existing models involve a singlelayer design and regularly a coaxial feed $[34,35]$ is utilized to attach the antenna to the transceiver. This type of feed structure is firm and is often annoying to the wearer. Similarly, using microstrip feed to the antenna is not the greatest solution because of the unnecessary parasitic radiations from the feed line and the radiating element. However, these problems can be mitigated by situating the feed line beneath the antenna ground plane, which can protect the feed line and the transceiver from the radiating antenna. The power is transferred from the feed line to the radiating element through an aperture in the ground plane that leads to an aperture-coupled patch antenna. The Aperture Coupled Wearable Patch Antenna (AC-WPA) serves the purpose. Its structure involves a ground plane sandwiched between two different substrates. The radiating patch is placed on the antenna substrate and a feed line is seated on the base of the feed substrate as shown in Figure 5.

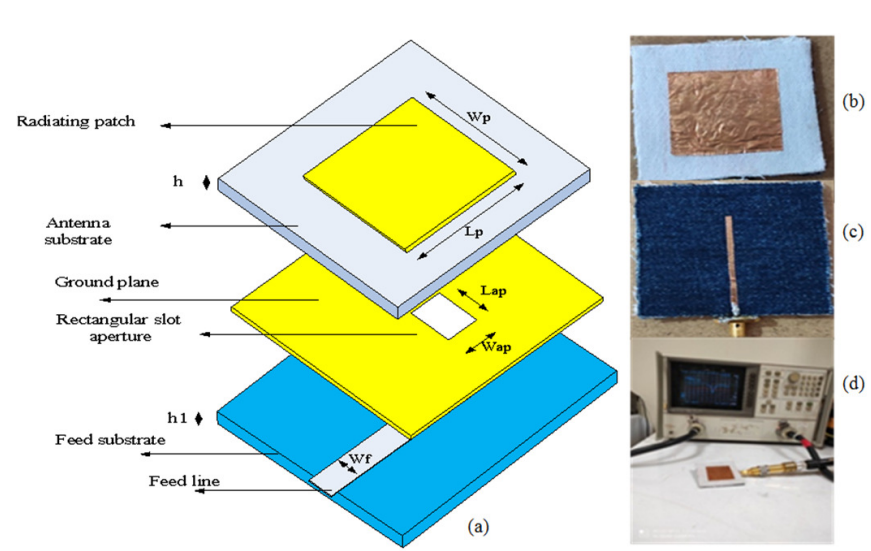

Fig. 5. AC-WPA: (a) Scheme, (b) front view and (c) back view of the fabricated prototype, (d) experimental setup.

All the rigid cables are replaced with a simple transmission line, and the power is coupled through a small aperture of arbitrary shape in the ground plane, which justifies the name of the antenna. Flexible jeans and wash cotton were chosen as the feed and antenna substrates since they are typical, durable, inelastic, and of low cost. Design studies were carried out using

\begin{tabular}{|c|c|c|c|c|}
\hline \multirow{2}{*}{ Patch } & \multirow{2}{*}{$\begin{array}{l}\text { Adhesive } \\
\text { copper }\end{array}$} & $W_{p}(\mathrm{~mm})$ & \multicolumn{2}{|c|}{$L_{p}(\mathrm{~mm})$} \\
\hline & & 43 & \multicolumn{2}{|c|}{40} \\
\hline \multirow{2}{*}{$\begin{array}{l}\text { Antenna } \\
\text { substrate }\end{array}$} & \multirow{2}{*}{$\begin{array}{l}\text { Wash } \\
\text { cotton }\end{array}$} & $h(\mathrm{~mm})$ & $\varepsilon_{r}$ & $\tan \delta$ \\
\hline & & 2.56 & 1.5 & 0.025 \\
\hline \multirow{2}{*}{$\begin{array}{c}\text { Ground } \\
\text { plane }\end{array}$} & \multirow{2}{*}{$\begin{array}{l}\text { Adhesive } \\
\text { copper }\end{array}$} & $W_{g}(\mathrm{~mm})$ & \multicolumn{2}{|c|}{$L_{g}(\mathrm{~mm})$} \\
\hline & & 65 & \multicolumn{2}{|c|}{65} \\
\hline \multirow{2}{*}{ Aperture } & & $W_{a p}(\mathrm{~mm})$ & \multicolumn{2}{|c|}{$L_{a p}(\mathrm{~mm})$} \\
\hline & & 3.5 & \multicolumn{2}{|c|}{20} \\
\hline \multirow{2}{*}{$\begin{array}{c}\text { Feed } \\
\text { substrate }\end{array}$} & \multirow{2}{*}{ Jeans } & $h(\mathrm{~mm})$ & $\varepsilon_{r}$ & $\tan \delta$ \\
\hline & & 1.15 & 1.7 & 0.02 \\
\hline \multirow{2}{*}{ Feed line } & \multirow{2}{*}{$\begin{array}{l}\text { Adhesive } \\
\text { copper }\end{array}$} & $W_{f}(\mathrm{~mm})$ & \multicolumn{2}{|c|}{$l_{f}(\mathrm{~mm})$} \\
\hline & & 1.5 & \multicolumn{2}{|c|}{22.5} \\
\hline
\end{tabular}
the electromagnetic simulator CST MW Studio and the acquired optimized dimensions are tabulated in Table IV.

TABLE IV. OPTIMIZED DIMENSIONS OF THE AC-WPA

The adopted feeding method produces a higher bandwidth than the other feeding methods because of its impedance transformation behavior. In practical applications, the transceiver is directly connected to the feed line which couples the power to the patch through an aperture placed exactly in the middle under it. The prototype is built according to the specifications and is shown in Figure 5.

The AC-WPA is represented in its electrical equivalent circuit model to gain insight into the underlying electromagnetic behavior. The equivalent circuit of AC-WPA practically is complex and consists of lumped RLC elements, ideal transformer, and transmission line segment to represent the radiating patch and coupling slot. A simple equivalent model is adopted here, in which the optimized parameter values are shown directly in the circuit. The circuit simulations were carried out in ADS, whereas the electromagnetic simulator CST MWS was applied to achieve the AC-WPA design and optimization, which are shown in Figure 6(a). 
(a)

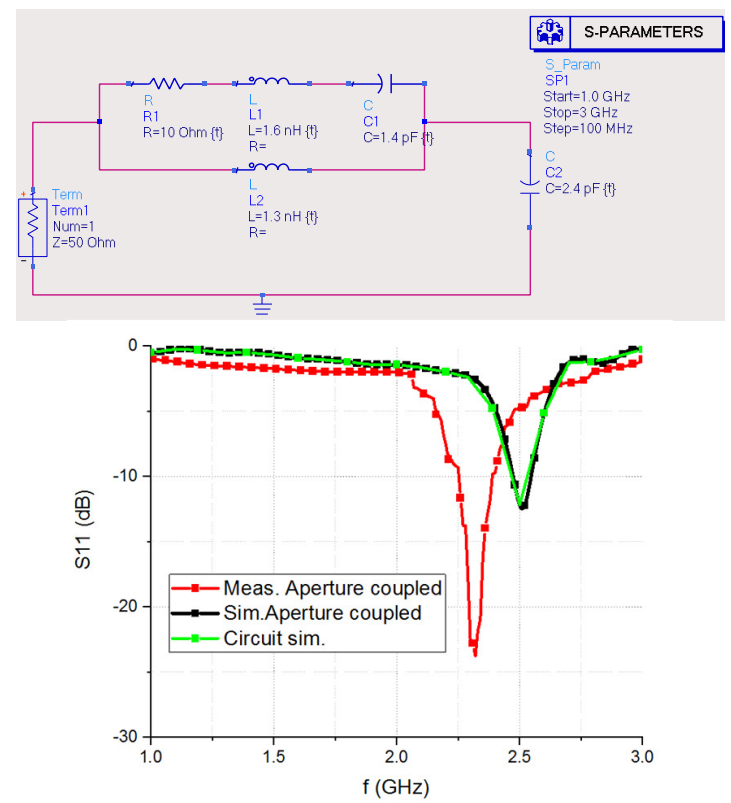

Fig. 6. (a) Circuit model, (b) reflection coefficient curve of AC-WPA.

It can be observed that there is a close relationship between the simulated and the measured values. However, proper care and attention must be given while assembling the multilayer structure manually, because even for small misalignment between the feed line, the slot, and the patch there is variation in the performance result. Moreover, high fabrication tolerances exist while working on textiles compared to the traditional substrates. All these circumstances lead to some measurement deviation in the resonance frequency as can be seen in Figure 6(b).

\section{BENDING CHARACTERIZATION AND ELECTRICAL MODELING}

The bent wearable patch antenna's geometry is modeled as a cylindrical cavity [36]. The geometry of the foam cylinders upon which the textile antennas are wrapped around is shown in Figure 7(a). For both inset fed and aperture coupled antennas, patch and ground planes were modeled as perfect electric conductors and the remaining four sides as perfect magnetic conductors. Hence this arrangement forms a cavity bounded by electric and magnetic walls at:

$$
\rho=r, \rho=r+h, \varphi= \pm \frac{\beta}{2}, \text { and } Z .= \pm L / 2
$$

The Maxwell's field equations are:

$$
\begin{aligned}
& E=-\nabla X F-j w \mu A+\frac{1}{j w \varepsilon} \nabla(\nabla . A) \\
& H=-\nabla X A-j w \mu F+\frac{1}{j w \varepsilon} \nabla(\nabla . F)
\end{aligned}
$$

The fields inside the cylindrical cavity are obtained by imposing the boundary conditions on Maxwell's equations. By solving these equations, one can get the relations for T.E. and T.M. modes, from which a relation between resonant frequency and bending radius was found analytically. To give an outlook to WBAN applications, it is essential to explore certain bending radius/angles per antenna width/length. From the circuit analysis point of view, the bending of the patch antenna changes length, thereby altering the antenna's E-field, which can be validated by changing the capacitance between the antenna element and the ground plane. In general, bending of the antenna brings discontinuity, i.e. the electric field becomes strongest in that particular part while the magnetic field shows a minimal effect. This indicates that the inductive loading doesn't get affected. The capacitive loading, also known as tuning capacitor, is denoted by $C_{t}$. As the bending radius increases, the capacitive loading becomes small [37]. The simulated circuit parameters for the patch antenna bent in the E-plane are shown in Figure 7(b). Comparing the flat case with the bent cases, it is observed that the capacitance $C 2$ decreases and $L 2$ increases. The product L.C increases when bending becomes critical, which means that the resonance frequency shifts to a lower frequency band.

(a)

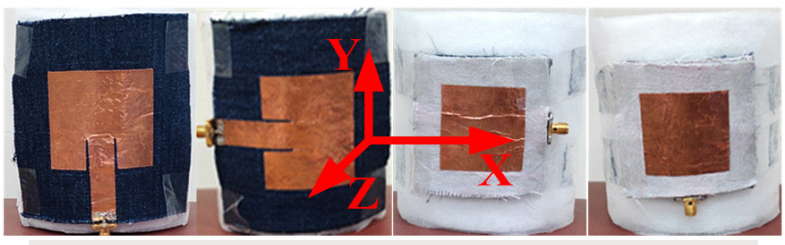

(b)

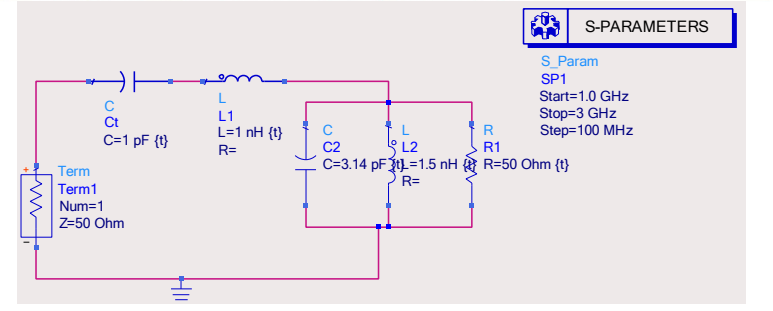

Fig. 7. (a) Antennas wrapped around foam cylinders in E, H-plane directions, (b) equivalent circuit of a bent patch antenna.

\section{RESULTS AND DISCUSSION}

Although the performance of the flexible antennas can be upgraded with united solutions for wearable applications, the development and optimization of such materials still require further characterization and improvement. Here a comparison is made for bending variations for different feeds of patch antennas where four different scenarios are considered. These radii are sensibly considered to mimic the chest and arm sizes of the human body [38]. These deformations were conducted to test their capability to resist a certain amount of structural bending.

\section{A. Effect on Resonant Frequency and Impedance Match}

Simulations were carried out over the frequency range of $1.0-3.0 \mathrm{GHz}$. The proposed textile antennas have been fabricated, and the resultant reflection coefficient is measured using the Vector Network Analyzer (VNA) Hewlett Packard 8719A. When these antennas are wrapped around the cylindrical foam surfaces, the simulated resonant frequency appears to be dependent on the antenna curvature, more particularly for the antenna bending in the direction of length as for a microstrip radiator the electric field lines are oriented 
along the length and magnetic field lines along the width. Therefore a shift in resonant frequency appeared as the effective length of the patch is decreased when it is bent lengthwise.

(a)

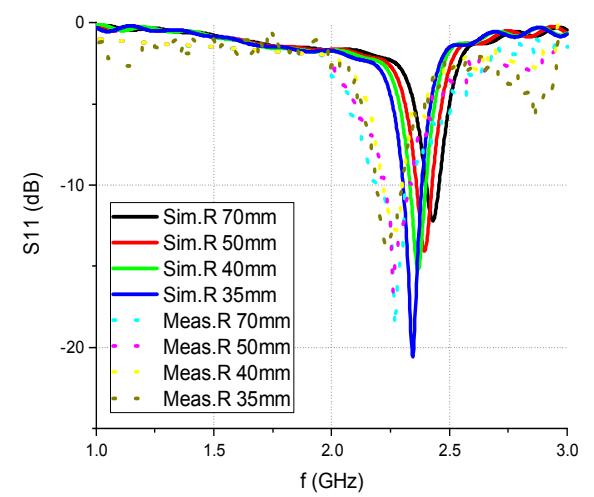

(b)

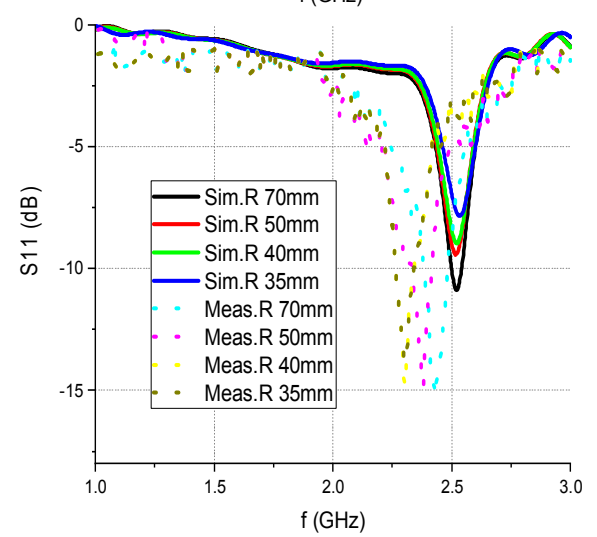

(c)

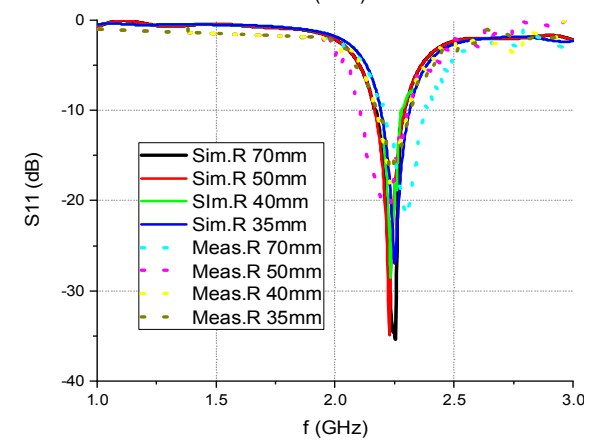

(d)

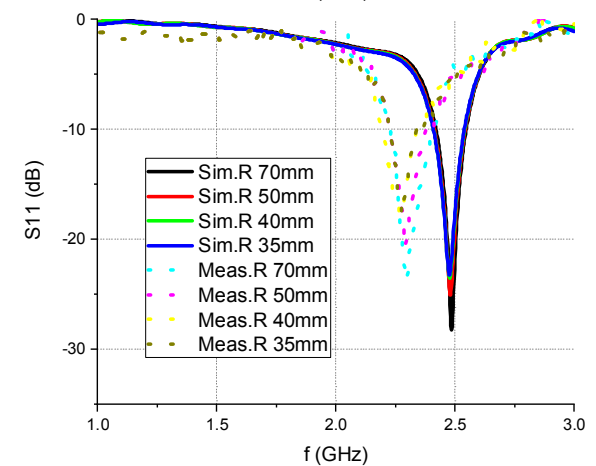

Fig. 8. Return loss variations for different bending cases for (a) AC-WPA, on the E-plane, (b) inset fed patch antenna on the E-plane, (c) AC-WPA on the H-plane, and (d) inset fed patch antenna on the H-plane.
If the tendency of detuning of the simulated resonant frequency is considered and graphed for different bending cases, it is worth noting that the more the antenna is bent in the E-plane, in general, the more the effective length gets reduced, and so the resonant frequency gets shifted to the higher band as shown in Figure 8(a) and 8(b) for the AC-WPA and the inset fed patch antenna respectively [39]. On the other hand, the Hplane bending shows minute, almost negligible, variations in resonant frequency (Figure $8(\mathrm{c}), 8(\mathrm{~d})$ ). It can be seen that the reflection coefficient increases as the bending becomes critical, i.e. the antenna operates ordinarily. For the AC-WPA, the frequency detuning is approximately $16 \%$ for severe bending in the E-Plane, and the deviation in the resonant frequency is small in the H-Plane. The return loss of the bent AC antenna is large, so a large amount of energy enters the antenna and hence efficient antenna performance is obtained. The same is applicable for any candidate antenna.

\section{B. Effect on Electric Field Intensity}

The electric field intensity can be better understood when the antenna bending occurs on a foam cylinder. The distribution of the E-field for both the proposed antennas under different bending radii is shown in Figure 9. It can be observed that the E-field is small at the center, and maximum at the sides of the patch for the flat antenna candidates. Instead, for both the antennas, there is an insignificant effect on their E-field behavior under bending situations, in which maximum occurs at the sides of the patch. Generally, for the inset fed patch antenna, the electric field, and thus the current flow, is associated with the length, whereas the magnetic field with the width. Exposing antennas to lengthwise bending, influences on the current flow and the electric field are expected, while there is marginal impact when the bending occurs in the width direction. The change in the distance traveled by the current between the opposing ends of the patch antenna due to the bending of the materials leads to a reduction in the length of the patch.

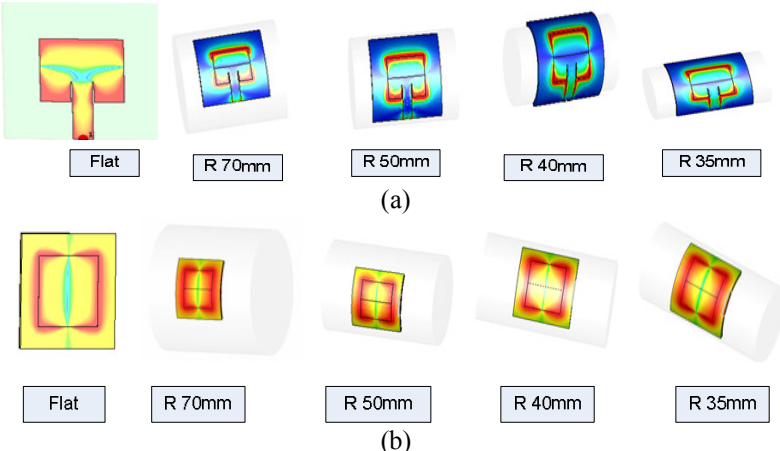

Fig. 9. Electric filed variations of (a) inset fed antenna, (b) AC-WPA on different bending fixtures.

\section{Effects on the Radiation Pattern}

Figure 10 shows the E-plane 2D radiation patterns for the planar and bent antennas. Meanwhile, for all the bending cases, the forward gain shows slight variations due to the high bending radius, which gives some difficulties to the antenna to radiate appropriately. It is instinctively clear that antenna 
bending widens the radiation pattern in the bending plane, which leads to gain reduction. Different bending radii do not have a significant effect on the antenna radiation pattern. However, the efficiency of the proposed antenna is marginally reduced as the antenna bending is increased, but the antenna still operates efficiently at an acceptable level as shown in Table V. Another main consequence was obtained in terms of $3 \mathrm{~dB}$ angular beam width, which is experienced as an increment when bending becomes critical.

(a)
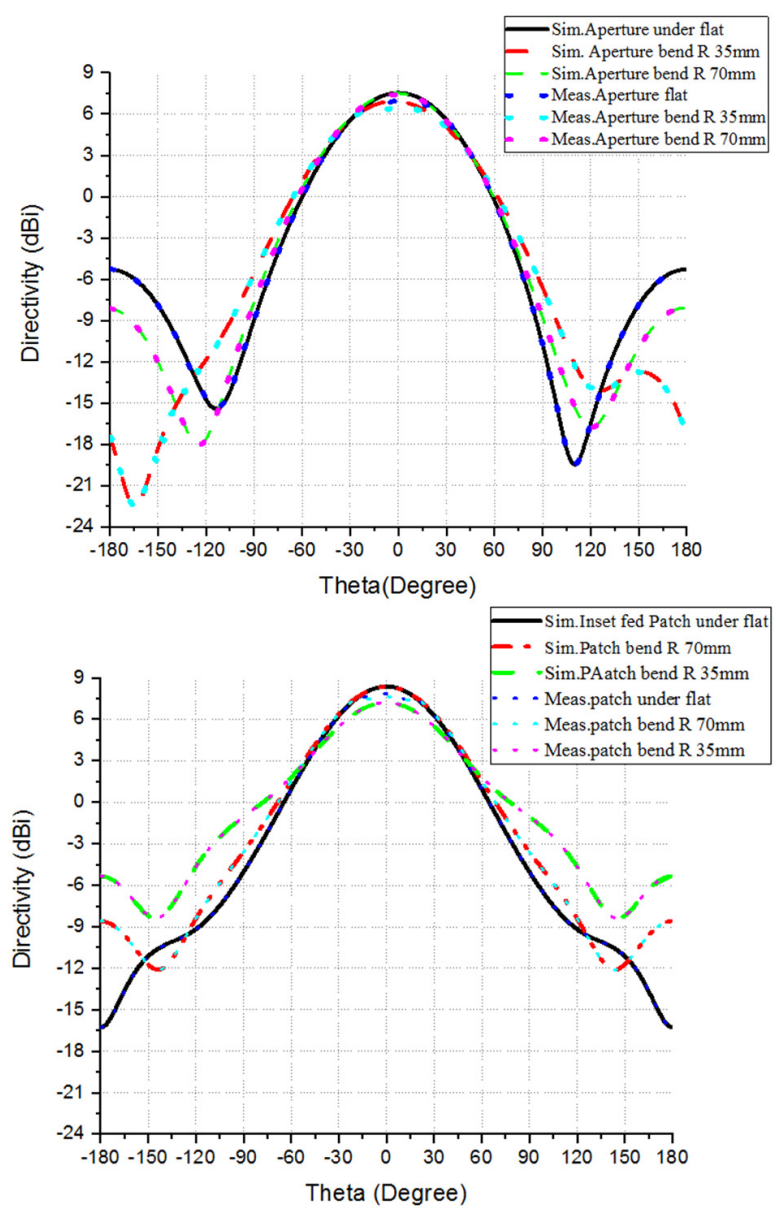

Fig. 10. 2D Radiation pattern variations of (a) aperture coupled, (b) inset fed wearable patch antenna in different bending situations.

TABLE V. GAIN AND EFFICIENCY VARIATIONS OF THE PROPOSED ANTENNAS FOR DIFFERENT BENDING RADII

\begin{tabular}{|c|c|c|c|c|}
\hline \multirow{2}{*}{$\begin{array}{c}\text { Cylinder } \\
\text { Radius(mm) }\end{array}$} & \multicolumn{2}{|c|}{ Gain (dBi) } & \multicolumn{2}{c|}{ Efficiency (\%) } \\
\cline { 2 - 5 } & Inset fed & $\begin{array}{c}\text { Aperture } \\
\text { coupled }\end{array}$ & Inset fed & $\begin{array}{c}\text { Aperture } \\
\text { coupled }\end{array}$ \\
\hline Flat & 6.12 & 4.84 & 58.61 & 53.95 \\
\hline $70 \mathrm{~mm}$ & 6.01 & 4.50 & 58.34 & 46.02 \\
\hline $50 \mathrm{~mm}$ & 5.74 & 4.46 & 58.47 & 55.08 \\
\hline $40 \mathrm{~mm}$ & 5.41 & 4.41 & 59.56 & 55.08 \\
\hline $35 \mathrm{~mm}$ & 5.03 & 4.13 & 60.06 & 52.72 \\
\hline
\end{tabular}

\section{CONCLUSIONS}

This paper focused on developing electrical equivalents of bending and its feeding effects on wearable textile antennas when bending occurs on a certain radius. Two exciting feed types were selected on the textile patch antenna and input impedance, resonance frequency, electric field intensity, and radiation pattern were investigated. These are the most significant parameters to be observed before focusing on the bending effects. It was found that the E-Plane bending has a dominant impact on the impedance matching for both textile antennas. This result holds for all antenna candidates because the resonant length changes when the antenna is bent. The results showed that the aperture coupled antenna has a minimal bending influence on the impedance matching and resonant frequency, proving the robustness of the antenna under these effects at the cost of complexity. Moreover, the feed type removes the usage of rigid cables and unnecessary radiation from the feeds. The less cross-polar level makes it a better candidate for wearable applications. Also, the electric field intensity and gain have minimal effect on bending for both the antenna candidates. Therefore, aperture coupled wearable antennas are far better regarding the bending performance despite their structural complexity.

\section{REFERENCES}

[1] A. Sabban, "Small wearable antennas for wireless communication and medical systems," in IEEE Radio and Wireless Symposium, Anaheim, CA, USA, Jan. 2018, pp. 161-164, https://doi.org/10.1109/RWS. 2018.8304974.

[2] S. Karthikeyan, Y. V. Gopal, V. G. N. Kumar, and T. Ravi, "Design and Analysis of Wearable Antenna for Wireless Body Area Network," IOP Conference Series: Materials Science and Engineering, vol. 590, no. 1, Jul. 2019, Art. no. 012022, https://doi.org/10.1088/1757-899X/590/1/ 012022 .

[3] S. Alotaibi and A. A. Alotaibi, "Design of a Planar Tri-Band Notch UWB Antenna for X-Band, WLAN, and WiMAX," Engineering, Technology \& Applied Science Research, vol. 10, no. 6, pp. 6557-6562, Dec. 2020, https://doi.org/10.48084/etasr.3904.

[4] H. Alsaif, "Compact Hexagonal Monopole Antenna for Lower 5G Bands," Engineering, Technology \& Applied Science Research, vol. 9 no. 3, pp. 4200-4202, Jun. 2019, https://doi.org/10.48084/etasr.2714.

[5] L. Corchia, G. Monti, E. De Benedetto, and L. Tarricone, "Wearable Antennas for Remote Health Care Monitoring Systems," International Journal of Antennas and Propagation, vol. 2017, Dec. 2017, Art. no. e3012341, https://doi.org/10.1155/2017/3012341.

[6] M. A. R. Osman, M. K. A. Rahim, N. A. Samsuri, H. A. M. Salim, and and M. F. Ali, "Embroidered Fully Textile Wearable Antenna for Medical Monitoring Applications," Progress In Electromagnetics Research, vol. 117, pp. 321-337, 2011, https://doi.org/10.2528/ PIER1 1041208.

[7] C. Hertleer, H. Rogier, L. Vallozzi, and L. Van Langenhove, "A Textile Antenna for Off-Body Communication Integrated Into Protective Clothing for Firefighters," IEEE Transactions on Antennas and Propagation, vol. 57, no. 4, pp. 919-925, Apr. 2009, https://doi.org/10. 1109/TAP.2009.2014574.

[8] T. Haagenson, S. Noghanian, P. de Leon, and Y. Chang, "Textile Antennas for Spacesuit Applications: Design, simulation, manufacturing, and testing of textile patch antennas for spacesuit applications.," IEEE Antennas and Propagation Magazine, vol. 57, no. 4, pp. 64-73, Dec. 2015, https://doi.org/10.1109/MAP.2015.2453890.

[9] O. Sahin, O. Kayacan, and E. Bulgun, "Smart Textiles for Soldier of the Future," Defence Science Journal, vol. 55, no. 2, pp. 195-205, 2005, https://doi.org/10.14429/DSJ.55.1982.

[10] P. Nepa and H. Rogier, "Wearable Antennas for Off-Body Radio Links at VHF and UHF Bands: Challenges, the state of the art, and future trends below $1 \mathrm{GHz}, "$ IEEE Antennas and Propagation Magazine, vol. 57, no. 5, pp. 30-52, Jul. 2015, https://doi.org/10.1109/MAP.2015. 2472374 . 
[11] R. Swetha and L. Anjaneyulu, "Compact Circularly Polarized Patch Antenna for WiMAX Applications with Improved Impedance Bandwidth and Axial Ratio," Engineering, Technology \& Applied Science Research, vol. 10, no. 1, pp. 5104-5107, Feb. 2020, https://doi. org/10.48084/etasr.3207.

[12] I. Agbor, D. K. Biswas, and I. Mahbub, "A comprehensive analysis of various electro-textile materials for wearable antenna applications," in Texas Symposium on Wireless and Microwave Circuits and Systems, Waco, TX, USA, Apr. 2018, pp. 1-4, https://doi.org/10.1109/ WMCaS.2018.8400628.

[13] B. M. Nikolova, G. T. Nikolov, E. E. Gieva, and I. N. Ruskova, "Dielectric Properties Measurement of Flexible Substrates," in IEEE XXVII International Scientific Conference Electronics - ET, Sozopol, Bulgaria, Sep. 2018, pp. 1-4, https://doi.org/10.1109/ET.2018.8549643.

[14] S. Sankaralingam and B. Gupta, "Determination of Dielectric Constant of Fabric Materials and Their Use as Substrates for Design and Development of Antennas for Wearable Applications," IEEE Transactions on Instrumentation and Measurement, vol. 59, no. 12, pp. 3122-3130, Sep. 2010, https://doi.org/10.1109/TIM.2010.2063090.

[15] M. I. Ahmed, M. F. Ahmed, and A. A. Shaalan, "Investigation and Comparison of $2.4 \mathrm{GHz}$ Wearable Antennas on Three Textile Substrates and Its Performance Characteristics," Open Journal of Antennas and Propagation, vol. 5, no. 3, pp. 110-120, Sep. 2017, https://doi.org/ 10.4236/ojapr.2017.53009.

[16] L. Song and Y. Rahmat-Samii, "A Systematic Investigation of Rectangular Patch Antenna Bending Effects for Wearable Applications," IEEE Transactions on Antennas and Propagation, vol. 66, no. 5, pp. 2219-2228, Feb. 2018, https://doi.org/10.1109/TAP.2018.2809469.

[17] I. Adam et al., "Investigation on Wearable Antenna under Different Bending Conditions for Wireless Body Area Network (WBAN) Applications," International Journal of Antennas and Propagation, vol. 2021, Jun. 2021, Art. no. e5563528, https://doi.org/10.1155/2021/ 5563528.

[18] Md. M. Ur Rashid, A. Rahman, L. C. Paul, and A. Krishno Sarkar, "Performance Evaluation of a Wearable $2.45 \mathrm{GHz}$ Planar Printed Meandering Monopole Textile Antenna on Flexible Substrates," in 1st International Conference on Advances in Science, Engineering and Robotics Technology, Dhaka, Bangladesh, May 2019, pp. 1-6, https://doi.org/10.1109/ICASERT.2019.8934451.

[19] R. Sanchez-Montero, P.-L. Lopez-Espi, C. Alen-Cordero, and J.-A. Martinez-Rojas, "Bend and Moisture Effects on the Performance of a UShaped Slotted Wearable Antenna for Off-Body Communications in an Industrial Scientific Medical (ISM) 2.4 GHz band," Sensors, vol. 19, no. 8, Jan. 2019, Art. no. 1804, https://doi.org/10.3390/s19081804.

[20] N. I. Zaidi, M. T. Ali, N. H. A. Rahman, M. F. Yahya, and M. S. A. Nordin, "Analysis on different shape of textile antenna under bending condition for GPS application," Bulletin of Electrical Engineering and Informatics, vol. 9, no. 5, pp. 1964-1970, Oct. 2020, https://doi.org/ 10.11591/eei.v9i5.2185.

[21] S. M. Abbas, K. P. Esselle, L. Matekovits, M. Rizwan, and L. Ukkonen, "On-body antennas: Design considerations and challenges," in URSI International Symposium on Electromagnetic Theory, Espoo, Finland, Aug. 2016, pp. 109-110, https://doi.org/10.1109/URSI-EMTS.2016. 7571326.

[22] E. M. Wissem, I. Sfar, L. Osman, and J.-M. Ribero, "A Textile EBGBased Antenna for Future 5G-IoT Millimeter-Wave Applications," Electronics, vol. 10, no. 2, Jan. 2021, Art. no. 154, https://doi.org/ 10.3390/electronics10020154.

[23] I. R. Sheeba and T. Jayanthy, "Analysis and implementation of Flexible Microstrip Antenna of soft substrates with different Feeding Techniques for ISM Band," in IEEE International Conference on System, Computation, Automation and Networking, Pondicherry, India, Mar. 2019, pp. 1-5, https://doi.org/10.1109/ICSCAN.2019.8878819.

[24] H. I. Azeez, W.-S. Chen, C.-K. Wu, C.-M. Cheng, and H.-C. Yang, "A Simple Resonance Method to Investigate Dielectric Constant of Low Loss Substrates for Smart Clothing," Sensors and Materials, vol. 30, no. 3, pp. 595-608, 2018, https://doi.org/10.18494/SAM.2018.1828.

[25] P. J. Low, F. Esa, K. Y. You, and Z. Abbas, "Estimation of Dielectric Constant for Various Standard Materials using Microstrip Ring
Resonator," Journal of Science and Technology, vol. 9, no. 3, pp. 55-59, Dec. 2017.

[26] K. Latti, J.-M. Heinola, M. Kettunen, J.-P. Strom, and P. Silventoinen, "A Review of Microstrip T-resonator Method in Determination of Dielectric Properties of Printed Circuit Board Materials," in IEEE Instrumentationand Measurement Technology Conference Proceedings, Ottawa, ON, Canada, May 2005, vol. 1, pp. 62-66, https://doi.org/ 10.1109/IMTC.2005.1604069.

[27] M. T. Jilani, M. T. Khan, S. M. Ali, M. Z. ur Rehman, and A. M. Khan, "A Brief Review of Measuring Techniques for Characterization of Dielectric Materials," International Journal of Information Technology and Electrical Engineering, vol. 1, no. 1, pp. 1-5, 2012.

[28] A. Rashidian, M. T. Aligodarz, and D. M. Klymyshyn, "Dielectric characterization of materials using a modified microstrip ring resonator technique," IEEE Transactions on Dielectrics and Electrical Insulation, vol. 19, no. 4, pp. 1392-1399, Aug. 2012, https://doi.org/10.1109/ TDEI.2012.6260016

[29] A. Y. I. Ashyap et al., "Compact and Low-Profile Textile EBG-Based Antenna for Wearable Medical Applications," IEEE Antennas and Wireless Propagation Letters, vol. 16, pp. 2550-2553, 2017, https://doi.org/10.1109/LAWP.2017.2732355.

[30] M. I. Ahmed, M. F. Ahmed, and and A. H. A. Shaalan, "Novel ElectroTextile Patch Antenna on Jeans Substrate for Wearable Applications," Progress In Electromagnetics Research C, vol. 83, pp. 255-265, 2018, https://doi.org/10.2528/PIERC18030309.

[31] G. Kumar and K. P. Ray, Broadband Microstrip Antennas. Boston, MA, USA: Artech House, 2003.

[32] C. A. Balanis, Antenna Theory: Analysis and Design, Fourth edition. New York, NY, USA: John Wiley \& Sons, 2015.

[33] R. Garg, P. Bhartia, I. J. Bahl, and A. Ittipiboon, Microstrip Antenna Design Handbook. Boston, MA, USA: Artech House, 2001.

[34] S. Ramdani, I. Pratama, and Basari, "Single Coaxial Feed Microstrip GPS Antenna Aimed at Wearable Device Application," in IEEE Conference on Antenna Measurements \& Applications, Kuta, Bali, Indonesia, Oct. 2019, pp. 247-250, https://doi.org/10.1109/ CAMA47423.2019.8959786.

[35] K. R. Rathod and B. K. Mishra, "Performance evaluation of linearly polarized, circularly polarized corner cut square using coaxial feed and rectangular slot textile antenna using CPW feed at $2.45 \mathrm{GHz}$," in International Conference \& Workshop on Electronics \& Telecommunication Engineering, Mumbai, India, Feb. 2016, pp. 37-45, https://doi.org/10.1049/cp.2016.1119.

[36] F. Boeykens, L. Vallozzi, and H. Rogier, "Cylindrical Bending of Deformable Textile Rectangular Patch Antennas," International Journal of Antennas and Propagation, vol. 2012, Apr. 2012, Art. no. e170420, https://doi.org/10.1155/2012/170420.

[37] L. C. Ping, "Circuit Model of Curved Ultra Wideband (UWB) Antenna," MATEC Web of Conferences, vol. 95, 2017, Art. no. 14011, https://doi.org/10.1051/matecconf/20179514011.

[38] A. Y. I. Ashyap et al., "Robust and Efficient Integrated Antenna With EBG-DGS Enabled Wide Bandwidth for Wearable Medical Device Applications," IEEE Access, vol. 8, pp. 56346-56358, 2020, https://doi.org/10.1109/ACCESS.2020.2981867.

[39] L. Z. Tung, G. A. Mahdiraji, and L. C. Ping, "Comparative Study between Planar and Bent Antenna Characterization," MATEC Web of Conferences, vol. 152, 2018, Art. no. 03002, https://doi.org/10.1051/ matecconf/201815203002. 